\title{
The role of regulatory credibility in effective bank regulation
}

\author{
Ephraim Clark ${ }^{\mathrm{a}, *}$, Octave Jokung ${ }^{\mathrm{b}}$ \\ a Middlesex University Business School, United Kingdom \\ ${ }^{\mathrm{b}}$ EDHEC Business School, France
}

\section{A R T I C L E I N F O}

\section{Article history:}

Received 7 August 2013

Accepted 10 March 2014

Available online 20 March 2014

\section{JEL classification:}

G28

Keywords:

Systemic risk

Micro-prudential regulation

Procyclicality

Regulated Brownian motion

Endogenous expectations

\begin{abstract}
A B S T R A C T
This paper develops a model of regulated Brownian motion with an endogenous profit term to analyze the role of regulatory credibility on the stability and productivity of the banking system. We show that when regulatory intervention is perfect and costless, the volatility of the system can be substantially reduced with no loss of productivity. In fact, perfect credibility can actually reduce the volatility of intrinsically risky banking systems below the volatility of intrinsically less risky systems as banks anticipate intervention and mitigate their investment behaviour accordingly. However, when the credibility of the regime is weakened because of increased uncertainty stemming from regulation, such as random costs or imperfect timing of regulatory intervention, both the stability and productivity of the financial system are impaired. Importantly, we find that in the presence of regulatory costs and imperfect credibility, there is no universal optimal intervention policy rule. The optimal regulatory system depends on the regulator's level of absolute risk aversion.
\end{abstract}

(c) 2014 The Authors. Published by Elsevier B.V. This is an open access article under the CC BY-NC-ND license (http://creativecommons.org/licenses/by-nc-nd/3.0/).

\section{Introduction}

This paper addresses the issue of systemic risk and financial regulation. More specifically, it looks at the interaction between two issues at the heart of systemic risk and successful financial regulation that have been neglected in the regulation literature. The first is associated with how effectively the regulatory framework is implemented and the second is how the regulated institutions react to the framework and its implementation.

A number of recent papers, such as Brunnermeier et al. (2009), Volker and Frenkel (2009), and Acharya and Richardson (2009), have highlighted the vulnerability of the overall financial system overseen by a regulatory framework based on micro-prudential regulations designed for regulating individual financial institutions. ${ }^{1}$ In this discussion, ${ }^{2}$ three aspects have been identified as particularly important. The first is associated with the procyclicality problem whereby prolonged periods of low volatility reduce statistical measures of risk and encourage excessive risk taking, which then

\footnotetext{
* Corresponding author. Tel.: +44 2084115130.

E-mail address: e.clark@mdx.ac.uk (E. Clark).

1 There is growing evidence that it does not ensure the integrity of the overall system and, that under certain conditions, this systemic risk is actually exacerbated by micro-prudential regulations (e.g. Acharya, 2009 and Zhou, 2010a).

2 For an overview on the causes of the systemic risk, see de Bandt and Hartmann (2001) and Allen et al. (2009).
}

rebounds when times get bad and generates excessive risk aversion. ${ }^{3}$ The second is cross-sectional and arises because banks are interconnected, either directly from operations such as interbank lending, ${ }^{4}$ or indirectly, through common exposures linked to individual diversification strategies. ${ }^{5}$ The third refers to liquidity and maturity mismatches via funding liquidity combined with adverse asset price movements due to low market liquidity (Acharya and Schnabl, 2009), or reliance on short term market financing to fund long term assets (Hellwig, 2008). ${ }^{6}$

The regulatory discussion of how these issues can be addressed has identified a number of promising policy instruments and highlighted some of the major problems associated with policy choice and implementation (Brunnermeier et al. (2009), Volker and Frenkel (2009), and Acharya and Richardson, 2009). Proposed policy instruments range from pro-cyclical capital ratios that incorporate liquidity risk to insurance policies and recapitalization

\footnotetext{
3 See, for example, Borio and Zhu (2008), Brunnermeier et al. (2009), and Shin (2009).

${ }^{4}$ See, for example, Allen and Gale (2000), Freixas et al. (2000), and Dasgupta (2004).

5 See, for example, Lagunoff and Schreft (2001), de Vries (2005) and Wagner (2010).

${ }^{6}$ Another branch of systemic risk studies how to measure systemic risk and how to evaluate the contribution of an individual financial institution to overall systemic risk See: Adrian and Brunnermeier (2008), Segoviano and Goodhart (2009), Tarashev et al. (2009a, 2009b), Huang et al. (2009) and Zhou (2010b).
} 
requirements. The problem is deciding on what regulatory instruments or combination of instruments would be most effective in reducing systemic risk and weighing their merits against their economic cost with respect to financial efficiency and innovation and how effectively they can be applied. The question of effective application is especially relevant for an industry that has a long and illustrious track record of capturing its regulators. This paper provides a framework for analyzing these aspects of regulatory efficiency and costs.

It starts from a micro-prudential framework and analyzes the effectiveness of the framework in terms of the trade-off between the productivity and stability of the system. It builds on the intuition that the effectiveness depends crucially on how the regime is perceived and how those perceptions impact the expectations and decisions of the regulated economic agents. As perceptions change, expectations change with consequent effects on decision making. For example, a strict regime that is perceived to be inefficiently managed will generate expectations that lead to a set of decisions that can be far different from those that would be taken if the regime were perceived to be efficiently managed. As the regime reveals itself over time, perceptions and expectations adjust and decision-making evolves accordingly. The main innovation is that the effect of endogenous expectations figures explicitly in the analysis.

Adopting the now standard representative agent framework, ${ }^{7}$ we develop a rational expectations model with an endogenous confidence term to analyse the effect of the credibility of discretionary regulation on the stability and productivity of the financial system. In this framework bank profits represent the productivity of the financial system, profit volatility represents the system's stability and the object of regulation is the rate of change of the size of the bank's balance sheet. ${ }^{8}$ We start with the base case and look at whether or not and to what extent, a perfectly credible, perfectly executed, costless regulatory policy aimed at reducing fluctuations in the size of bank balance sheets can improve the tradeoff between bank profits and profit volatility. We find that regulation generally yields substantial reductions in profit volatility with no loss in the level of profits themselves, but the effectiveness of regulation decreases exponentially as regulation is relaxed. Importantly, we also show that for inherently volatile banks very tight regulation can drive the volatility of net income below that of banks that are inherently less volatile. This counter-intuitive effect of regulation on the volatility of the banking system highlights the importance of regulatory credibility and suggests that the potential gain from financial regulation is greater in the inherently riskier financial systems.

In a second step we relax the assumption of costless implementation and introduce credibility as a cost in the sense that the costs of regulatory enforcement will be higher in a less credible system. ${ }^{9}$ When regulation entails costs, we find that the reduction in volatility is diminished with respect to perfect, costless regulatory interventions and the reduction in volatility that is achieved comes at the expense of lower profits. Furthermore, this negative effect on profits is most pronounced at the tightest regulatory bands where costless, perfect intervention is most effective.

In step number three, we relax the assumption of perfect intervention. We consider two types of imperfect intervention that reduce credibility: (1) To capture the effect of regulators not

\footnotetext{
7 The representative agent implies perfect procyclicality and cross sectional correlation.

${ }^{8}$ For the sake of generality, we focus on the whole balance sheet but the framework we propose can be applied to individual elements of the balance sheet to accommodate specific regulatory instruments, such as liquidity and capital ratios.

${ }^{9}$ For example, when the regulatory system is perceived as credible, intervention dictats will be observed with a minimum of oversight. When it is perceived as less credible more oversight is required.
}

intervening when they should or intervening when they should not, we allow costs to be random; (2) To capture the effect of regulators mis-timing their intervention by intervening too early or too late, we allow the timing of the intervention to be random. We find that random costs reduce the effectiveness of regulation by reducing profits for each unit of profit volatility. We also find that increased regulatory uncertainty stemming from imperfect timing of regulatory intervention, reduces both the stability and productivity of the financial system. Again, this negative effect on profits and volatility reduction is most pronounced at the tightest regulatory bands where costless, perfect intervention is most effective.

Finally, in one of the most interesting contributions of this paper, we use the tradeoff between profits and volatility to establish a link between optimal intervention policy and the regulator's attitude towards risk. We show that in the presence of less than perfect credibility, there is no universal optimal intervention policy rule. The optimal regulatory system depends on the regulator's level of absolute risk aversion. High levels of risk aversion are associated with tight regulation and frequent intervention while low levels of risk aversion are associated with light regulation and infrequent intervention.

The rest of the paper is organized as follows. In Section 2 we develop the model. In Section 3 we solve the model and analyse its parameters. Section 4 contains the results of the simulations and Section 5 gives our conclusions.

\section{The model}

Consider the representative banking group with total assets $q(t)$ financed by equity $k(t)$, private deposits $d(t)$, and borrowing from the central bank $b(t)$, such that $q(t)=k(t)+d(t)+b(t)$. Using the performance model based on return to total assets and the following notation:

$$
\begin{aligned}
& D(t)=\text { net income } \\
& m=\text { return on assets } \\
& a=\text { the investment coefficient (the increase in total assets per } \\
& \text { unit increase in expected net income) } \\
& \phi(t)=\text { the information set at time } t
\end{aligned}
$$

net income can be represented as a function of $m, q(t), a$, and the expected change in net income:

$D(t)=m q(t)+m a \frac{E[d D(t) / \phi(t)]}{d t}$

where $E$ is the expectation operator. The expected change in net income, $\frac{E[d D(t) / \phi(t)]}{d t}$, is the endogenous confidence term conditioned on the information set at time $t$.

Eq. (1) says that net income is equal to the return on assets multiplied by total assets $(m q(t))$ plus the return on assets $(m)$ multiplied by the increase in assets $(a)$ induced by the expected increment in net income $\left(\frac{E[d D(t) / \phi(t)]}{d t}\right)$.

Rearranging (1) gives:

$\frac{E[d D(t) / \phi(t)]}{d t}-\frac{1}{m a} D(t)=-\frac{1}{a} q(t)$

Integrating (2) with respect to $d t$ gives:

$D(t)=\frac{1}{a} \int_{t}^{\infty} e^{\frac{-(s-t)}{m a}} E[q(s) / \phi(t)] d s$

It is clear from Eq. (3) that the variable that drives net income is the expected size of the representative bank's assets and that regulating the banking system involves regulating the expected size of the representative bank's assets. In practice, regulation typically focuses on the composition of the bank's balance sheet rather than 
its size per se. However, the individual intervention techniques, such as risk linked capital requirements and liquidity ratios, ultimately determine the size of the bank system's balance sheet. In this paper, we are concerned with how the specific regulatory systems, laws and procedures are perceived rather than with the specific systems, laws and procedures themselves. ${ }^{10}$ Thus, in the interest of expository simplicity, but with no loss of generality, we focus on the effect of regulatory policy on the size of the balance sheet rather than on the details of regulation policy itself. With this in mind it is important to remember that more complicated policies are more difficult and costly to implement and administer.

In the simple system summarized in Eq. (3), one possible policy would be to determine the optimal level of credit and target directly the level of the bank's total assets. The obvious problem with this type of policy is that it is very restrictive and its usefulness to the real economy depends on the ability of the regulator to accurately determine what the optimal amount of credit should be. A more realistic and less restrictive policy would be to let the market forces in the economy determine the underlying supply and demand for credit and have the regulator maintain the stability of the system by controlling how fast credit can expand or contract. Under this policy, regulators time their interventions based on the rates of change of total assets rather than on their levels. Consequently, in our model, the variable that is the object of the authority's policy intervention is the rate of change of the bank's total assets. Let:

$f(t)=\frac{d q(t)}{d t}$

Suppose that in the absence of regulatory intervention, $f(t)$ follows a process of arithmetic Brownian motion:

$d f(t)=\alpha d t+\sigma d z(t)$

where $\alpha$ is the drift parameter, $\sigma$ is the standard deviation of $d f(t)$, and $z$ is a Weiner process with $E[d z(t)]=0$ and $E\left[(d z(t))^{2}\right]=d t$. The parameter $\sigma$ can be interpreted as the intrinsic volatility of the banking system.

Integrate (4) and take expectations:

$E[q(T)]=q(t)+\int_{t}^{T} E[f(s)] d s$

Put (6) into (3):

$D(t)=\frac{1}{a} \int_{t}^{\infty} e^{\frac{-(s-t)}{m a}}\left[q(t)+\int_{t}^{T} E[f(u)] d u\right] d s$

In Appendix A we show that the solution to (7) is given by:

$D(t)=m q(t)+m^{2} a f(t)+m^{3} a^{2} \alpha+A_{1} e^{\lambda_{1} f(t)}+A_{2} e^{\lambda_{2} f(t)}$

for some parameters $A_{1}, A_{2}$ determined later. In Appendix A we show that $\lambda_{1}>0$ and $\lambda_{2}<0$. The first three terms represent the normal movement in net income without regulatory intervention and the last two terms represent deviations from the market path due to intervention.

\section{The intervention technique}

Regulatory intervention can be introduced by placing upper and lower limits on $f(t)$ with intervention occurring as the rate of change of total assets approaches one of these limits. ${ }^{11}$ In this case,

\footnotetext{
${ }^{10}$ For example, the existence of banks deemed "too big to fail" reduces the credibility of the regulatory system.

11 The intervention technique in this stylized model involves using central bank credit $b(t)$ to regulate $q(t)$. For example, suppose a reserve ratio of $10 \%$ and no leakage from the system. If $b(t)$ changes by $1, q(t)$ will change by 10 . Of course, in practice other types of intervention, such as changes in capital requirements, are perfectly compatible with the model.
}

the evolution of $f(t)$ becomes regulated Brownian motion and the smooth and continuous nature of the interventions implies perfect and timely policy implementation.

Introducing regulatory intervention into the model is straightforward using standard techniques. The constants $A_{1}$ and $A_{2}$ can be solved from the smooth pasting conditions:

$\frac{\partial D}{\partial \bar{f}}=0$

$\frac{\partial D}{\partial \underline{f}}=0$

where $\bar{f}$ represents the upper limit and $f$ represents the lower limit.

Differentiating Eq. (8), evaluating the derivatives around the upper and lower limits, and solving the system gives:

$A_{1}=\frac{m^{2} a}{\lambda_{1}}\left[\frac{e^{\lambda_{2} \bar{f}}-e^{\lambda_{2} f}}{e^{\lambda_{1} \bar{f}+\lambda_{2} f}-e^{\lambda_{1} f+\lambda_{2} \bar{f}}}\right]$

$A_{2}=\frac{m^{2} a}{\lambda_{2}}\left[\frac{e^{\lambda_{1} f}-e^{\lambda_{1} \bar{f}}}{e^{\lambda_{1} \bar{f}+\lambda_{2} f}-e^{\lambda_{1} f-\lambda_{2} \bar{f}}}\right]$

where $A_{1}<0$ and $A_{2}>0$.

With $A_{1}$ and $A_{2}$ thus defined, the effects of the model's four economic parameters, $m, a, \alpha$, and $\sigma$, and two regulation policy parameters, $\bar{f}$ and $f$, on net income, $D$, can be determined. Increases in $m, a$, and $\alpha$ have a positive effect on net income whereas $\sigma$ does not figure directly in the solution. It figures indirectly through its effect on changes in $f(t)$. The effect of $\bar{f}$ and $f$ is to keep $D$ within a certain range of its long term equilibrium path. The smooth pasting conditions insure that the transition from one point to another within this range is smooth and continuous. Thus $\bar{f}$ and $f$ represent regulation policy guidelines and the smooth pasting conditions represent perfect and timely policy implementation within these guidelines.

\section{Results}

\subsection{Parameter values}

Simulating the model involves rewriting it in discrete time and determining the parameter values as well as the starting values for the endogenous variables. ${ }^{12}$ We want to analyze the effect of regulatory credibility on the trade-off between net income and the volatility of net income, where the volatility of net income represents the stability of the banking system. In the absence of regulation, the volatility of net income (the actual volatility of the banking system) depends directly on the intrinsic volatility of the banking system $(\sigma){ }^{13}$ To concentrate on how regulation affects this trade-off, we consider a bank with no growth so that $\alpha=0$ and set the other parameters relatively high. For the return on assets we let $m=0.15$; for the standard deviation of the change in the change in total assets we let $\sigma=\$ 100$ (1.5\%); and for the investment coefficient $a=5$ with an investment horizon of $T=10$ years. ${ }^{14}$ We set $f(0)=0$ and $q(0)=\$ 6667$ so that $D(0)=\$ 1000$.

\footnotetext{
12 Appendix B develops the discrete simulation model.

13 The volatility of net income is $\left(m^{2} \sigma_{q}^{2}+m^{2} a \sigma^{2} d t\right)^{\frac{1}{2}}$ where $\sigma_{q}^{2}$ is the variance of $q$.

14 This represents the cost of an investment that yields $\$ 1$ dollar of net income every year for 10 years in the formula:

$a=\$ 1(1+m)^{-1}+\$ 1(1+m)^{-2}+\ldots+\$ 1(1+m)^{-T}$

$a=\sum_{t=1}^{T} \$ 1(1+m)^{-t}$
} 
Starting with these values, we simulated each intervention band with $f=-\bar{f}$ and $\bar{f} \in\{1,2, \ldots, \infty\}$. Thus, the intervention band ranges from 2 to infinity with $T=10$ and $n=500$. Table 1 summarizes the initial parameter values.

\subsection{Perfect, costless regulatory intervention}

The first simulation deals with the case of perfect, costless regulation. Fig. 1 shows the different volatility levels for a wide range of intervention bands. We can see that discretionary intervention is most effective in reducing income volatility at very tight intervention bands (up to about plus or minus 3.5\%). As bands grow wider it becomes less and less effective. Another way of looking at this phenomenon is in terms of elasticities. Fig. 2 shows the elasticity of volatility reduction with respect to the intervention band. At a band of plus or minus $4.7 \%$, volatility becomes inelastic. Thus, we confirm the potential benefits of regulatory intervention. This result is unsurprising given the assumption of perfect and costless intervention. What is interesting, however, is the observation that regulation is most effective when bands are smallest and intervention is most frequent.

When we let the parameters vary, other interesting things happen. Fig. 3 shows that higher levels of return on assets $(m)$ or the investment coefficient $(a)$ increase the volatility of net income at all intervention bands. Given that banks can increase their return on assets and their asset base by reducing their capital requirements, this shows that a system of highly leveraged banks (high investment coefficients and high return on assets) ${ }^{15}$ is relatively more volatile (less stable) than a system with higher capital requirements. Interestingly, it is also less sensitive to regulatory intervention. When $\sigma$ varies, however, the effect is different. Remember that $\sigma$ represents the intrinsic volatility of the system. In Fig. 4 we see that tighter bands are more effective when $\sigma$ is higher. In fact, surprisingly and counter-intuitively, over a relatively long interval, regulatory intervention actually drives the volatility of net income for higher levels of $\sigma$ below the volatility for lower levels of $\sigma$. The reason for this counter-intuitive effect is that at high levels of $\sigma$ relative to the intervention band, the intervention effect on the expected change in total assets overwhelms the effect of stochastic movements within the band. In other words, for a given level of $f$, at higher levels of $\sigma$ the probability is higher that one of the limits will be reached, thereby triggering intervention by the regulator. Thus, banks anticipate intervention and mitigate their investment behavior more than they would if $\sigma$ were lower. This counterintuitive effect of regulation on the volatility of the banking system highlights the importance of regulatory credibility and suggests that the potential gain from financial regulation is greater in the inherently riskier financial systems. We address the choice of the optimal regulatory system in Section 4.5 .

\subsection{Perfect intervention with regulatory enforcement costs}

In practice, regulatory intervention is not costless. There are the fixed costs of gathering information and monitoring the banking system on a regular basis. The more frequent the interventions, that is, the smaller the intervention band, the higher the fixed costs will be. There are also the variable costs encountered when an act of intervention actually takes place. These costs accrue in the form of transaction costs associated with policy implementation and enforcement and the costs of compliance for the regulated bank. They reflect the credibility of the system as private agents react to the intervention. When the regulatory system is perceived as credible, intervention dictats will be observed with a minimum

\footnotetext{
${ }^{15}$ Here we assume that higher leverage increases the return on assets.
}

Table 1

Initial parameter values.

\begin{tabular}{llllllll}
\hline$a$ & $m$ & $\alpha$ & $\sigma$ & $T$ & $n$ & $f(0)$ & $q(0)$ \\
\hline 5.0 & 0.15 & 0 & 100 & 10 & 500 & 0 & 6667 \\
\hline
\end{tabular}

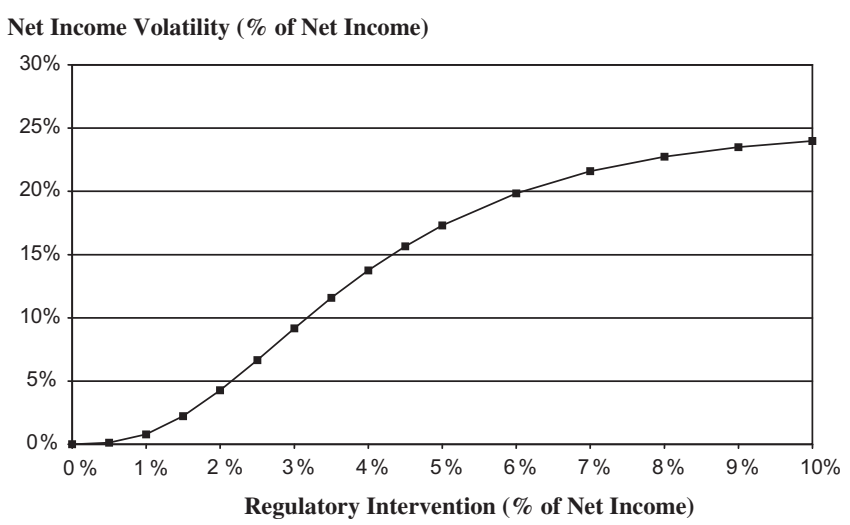

Fig. 1. Financial regulation and net income volatility.

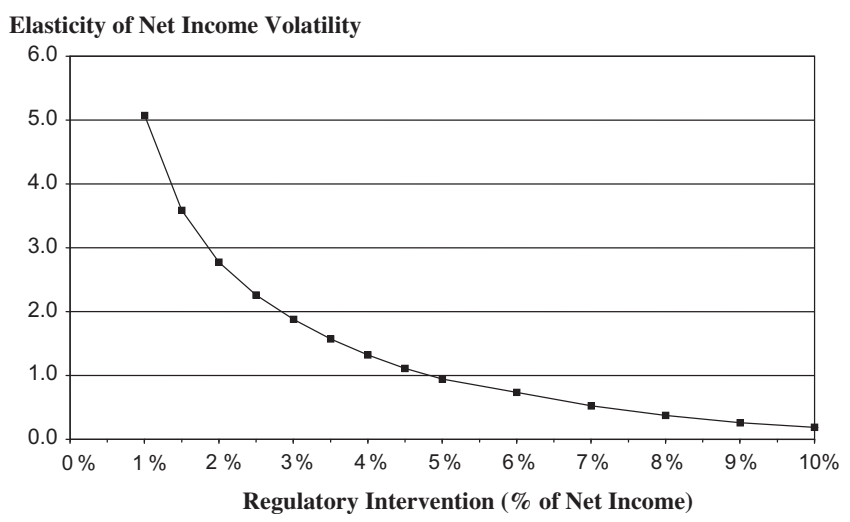

Fig. 2. Financial regulation and elasticity of net income volatility.

of oversight. When it is perceived as less credible more oversight with the associated costs is required. With this in mind, we focus on the variable costs associated with each intervention and assume that all regulatory costs accrue to the representative bank. We let intervention costs range from a low of $1 \%$ of expected net income to a high of $5 \%$. First, we look at the effect of intervention costs when intervention is perfect. In a second step, we look at the effects of bungled policy and timing imperfections.

Suppose that the variable cost per intervention is equal to $c$. The instantaneous cost, $C(t)$, is then given by

$C(t)=c\left[1-I_{[\bar{f}, f]}(f(t))\right]$

where $I_{\overline{[f} f]}(f(t))$ is an index with a value of 1 when $f(t)$ is inside the intervention range and a value of 0 when intervention takes place. Over the whole investment horizon total intervention costs will be equal to

Total cost $=\sum_{t=0}^{T} C(t)=c\left[T-\sum_{t=1}^{T} I_{[\bar{f}, f]}(f(t))\right]$

Total cost is equal to the cost of an individual intervention multiplied by the number of actual interventions. 
Net Income Volatility ( \% of Net Income)

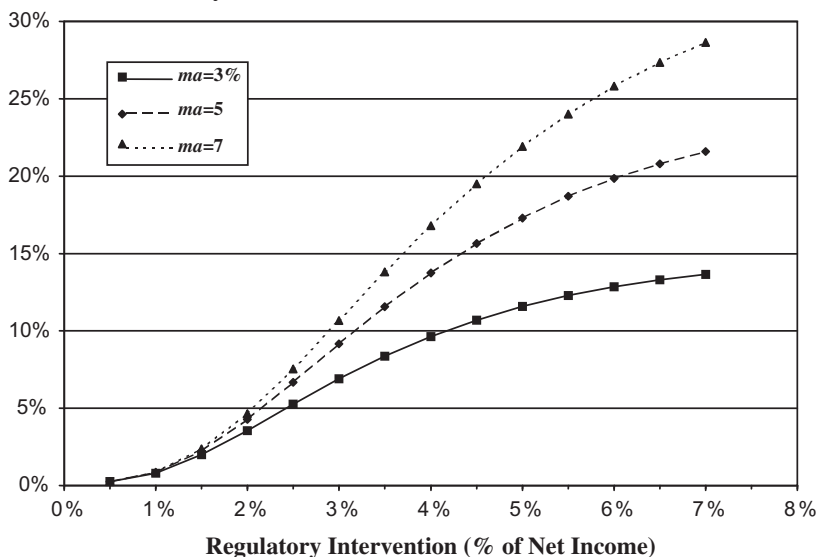

Fig. 3. Financial intervention and net income volatility effects of the investmentreturn $(\mathrm{ma})$.

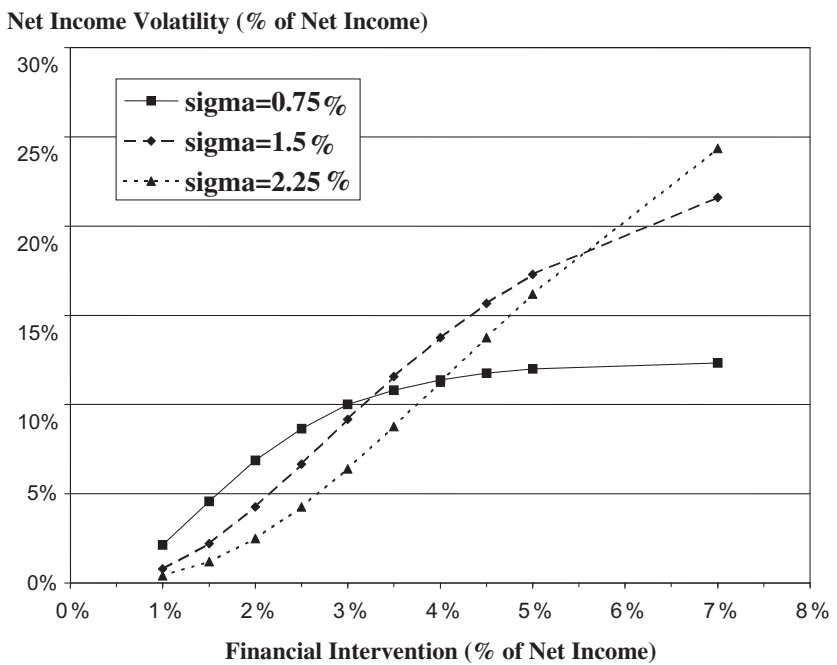

Fig. 4. Financial intervention and net income volatility effects of intrinsic volatility.

Fig. 5 shows the expected level of net income for different intervention bands when $c=50$, that is, $1 \%, 3 \%$, and $5 \%$ of expected profit. Remembering that in the absence of costs, the average level of net income is 1000 for all intervention bands, it is clear that intervention costs cause a substantial fall in the average level of net income - the higher the cost, the higher the fall. The fall is also most pronounced when bands are small and intervention is frequent. This result is obvious since it is a straightforward consequence of the definition of profits and how costs are calculated. However, what is interesting and less obvious is that intervention costs also have a similar adverse effect on income volatility. Fig. 6 compares volatility levels for different costs and different intervention bands. Volatility is higher in the presence of costs - the higher the costs, the higher the volatility. The effect of costs on volatility is also most pronounced when bands are smaller and intervention is more frequent. We can conclude that transactions costs reduce expected profitability as well as the effectiveness of intervention in reducing volatility. Furthermore, the cost effects occur in the interval where costless intervention is most effective in reducing volatility and it is a clear example of the tradeoff between productivity (measured as net income) and volatility due to intervention. In terms of elasticity with respect to the intervention band, Fig. 7 shows that volatility is most sensitive to changes in intervention at tighter levels of the effective intervention interval.

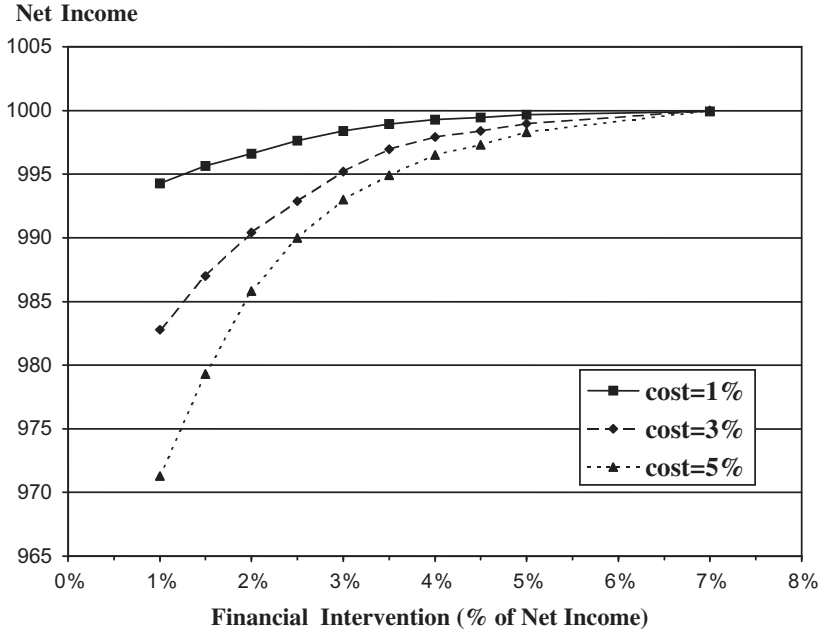

Fig. 5. Financial intervention and net income effects of intervention costs.

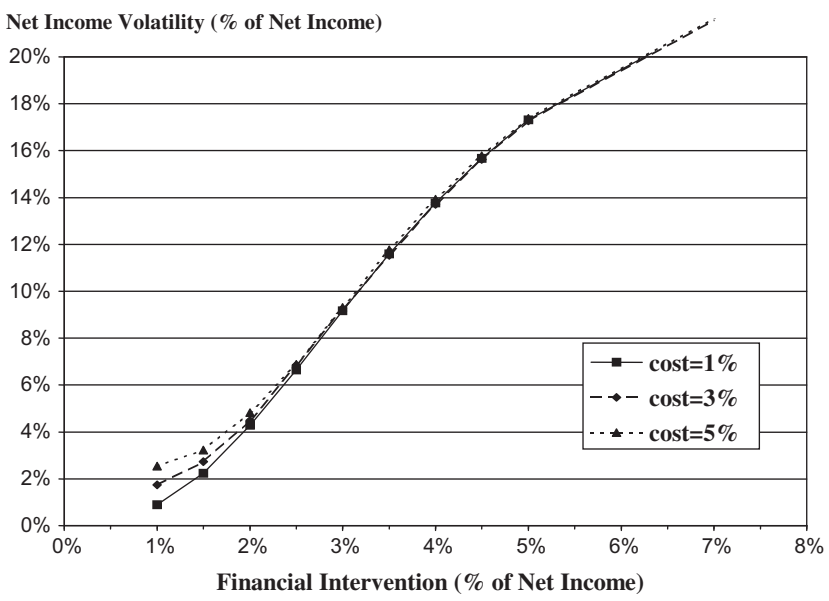

Fig. 6. Financial intervention and net income volatility effects of intervention costs

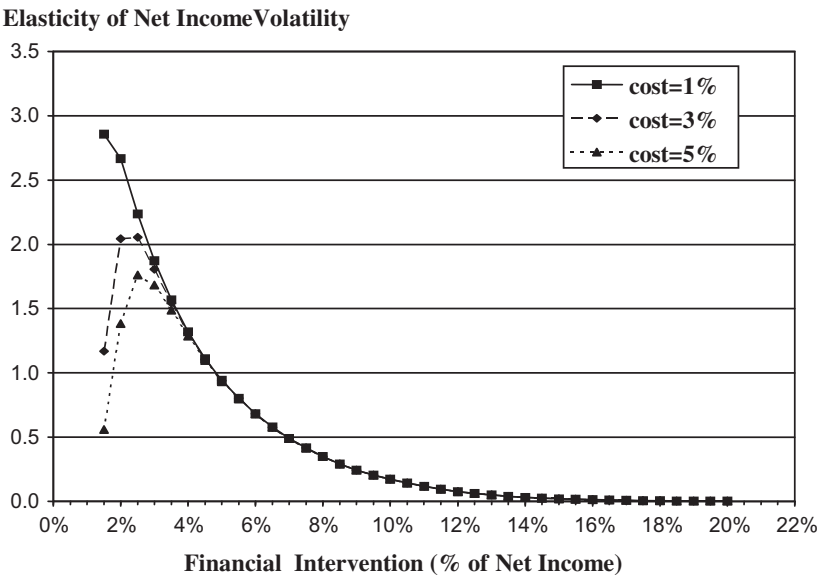

Fig. 7. Financial intervention and elasticity of net income volatility: Effects of intervention costs.

Now consider the case when costs themselves are random. An example of a situation of this type would be when the intervention is timely but the policy is inappropriate, e.g. limits on certain types of loans are imposed when, in fact, capital requirements should be increased. In this case the costs are equal to the transaction costs associated with policy implementation and enforcement and the 


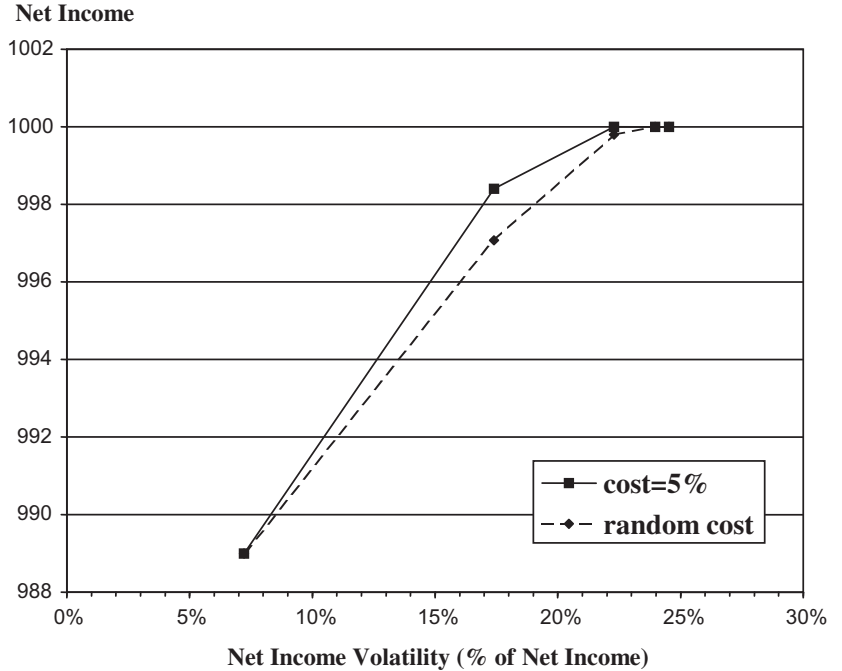

Fig. 8. Tradeoff between income level and net income volatility effects of constant and random intervention costs.

costs of compliance as well as the profits lost because of bad policy. Fig. 8 compares the tradeoff between average net income and volatility of net income when transaction costs are constant at $c=50$ and when they are random with the following probability distribution:

$P[c=25]=1 / 3$

$P[c=50]=1 / 3$

$P[c=75]=1 / 3$

such that $E[c]=5 \%$ - the average random cost is equal to the constant cost. In Fig. 8 we can see that there is a double negative effect. Net income is lower than it would be if costs were constant and volatility is higher.

\subsection{Imperfect, costless intervention}

Suppose now, that instead of perfect policy implementation there is a chance that the regulator will intervene a little too early or a little too late. This amounts to introducing a white noise, $\varepsilon$, surrounding $\bar{f}$ and $f$ so that the intervention will take place at $\bar{f}+\tilde{\varepsilon}$ and $f+\tilde{\varepsilon}$. For the sake of simplicity let $\tilde{\varepsilon}$ have the following probability distribution:

$P[\tilde{\varepsilon}=+\varepsilon]=1 / 3$

$P[\tilde{\varepsilon}=0]=1 / 3$

$P[\tilde{\varepsilon}=-\varepsilon]=1 / 3$

The smooth pasting conditions then become

$D^{\prime}(\bar{f}+\tilde{\varepsilon})=0$

$D^{\prime}(\underline{f}+\tilde{\varepsilon})=0$

and the constants of integration are

$A_{i}=A_{i}(\varepsilon) \quad i=1,2$

where

$A_{1}(x)=\frac{m^{2} a}{\lambda_{1}}\left[\frac{e^{\lambda_{2}(\bar{f}+x)}-e^{\lambda_{2}(f+x)}}{e^{\lambda_{1}(\bar{f}+x)+\lambda_{2}(f+x)}-e^{\lambda_{1}(f+x)+\lambda_{2}(\bar{f}+x)}}\right]$
Net Income Volatility (\% of Net Income)

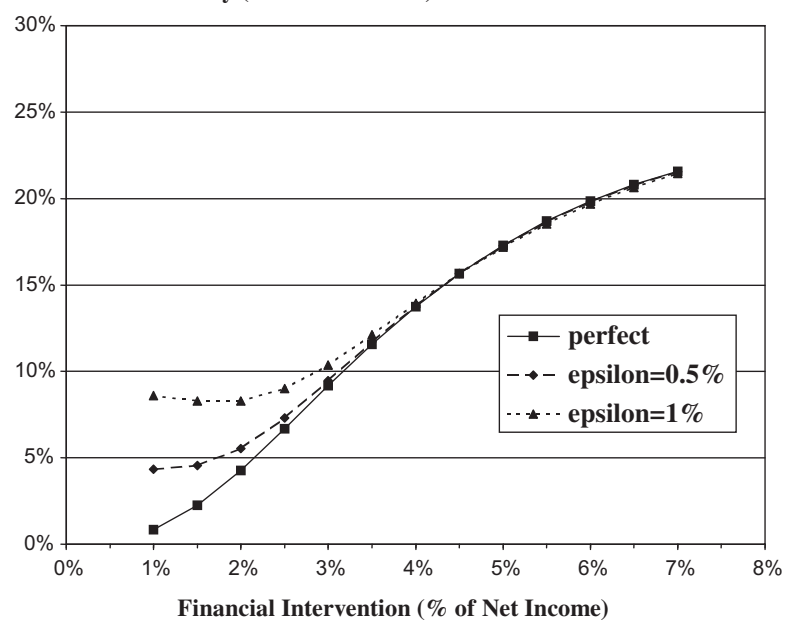

Fig. 9. Financial intervention and net income volatility effects of imperfect intervention.

$A_{2}(x)=\frac{m^{2} a}{\lambda_{2}}\left[\frac{e^{\lambda_{1}(\underline{f}+x)}-e^{\lambda_{1}(\bar{f}+x)}}{e^{\lambda_{1}(\bar{f}+x)+\lambda_{2}(\underline{f}+x)}-e^{\lambda_{1}(\underline{f}+x)+\lambda_{2}(\bar{f}+x)}}\right]$

Fig. 9 compares the results of imperfect intervention with the case of perfect intervention for different levels of the intervention band for two levels of $\varepsilon$. Imperfect intervention clearly increases volatility at all intervention bands up to $4 \%$ - the more imperfect the intervention (the larger is $\varepsilon$ ), the higher is the volatility. However, the effect is most pronounced over the interval where intervention is potentially the most effective.

Table 2 summarizes the foregoing results.

\subsection{The optimal level of intervention}

The foregoing discussion makes it possible to shed some light on the question of whether or not there is an optimum intervention level and, if there is, what it should be. When there are no costs associated with intervention, that is, when intervention is perfect and costless, the answer is straightforward. The optimal intervention band is the smallest intervention band. However, in the more realistic case where costs are present and/or intervention is imperfect, the optimal intervention band is situated somewhere between the smallest and no intervention at all. If we adopt the standard representative agent framework in mean-variance space, the optimal intervention level depends on the regulator's attitude towards risk. The more risk averse the regulator, the smaller the intervention band and vice versa. Consider, for example, the case of perfect intervention with constant intervention costs. In Fig. 8 we saw that there was a concave tradeoff between average net income and risk (volatility) reduction and that the concavity increases when costs are random. ${ }^{16}$ Let $k$ represent the economy's level of absolute risk aversion. ${ }^{17}$ To find the optimal band, we can maximize the function $E(D)-k \sigma(D)$. As we can see in Fig. 10, the optimal intervention band, given by $\bar{f}^{*}$, is found at the point of tangency of the straight line $k \sigma(D)$ with the curve determined by the ensemble of points $(E(D), \sigma(D))$.

\footnotetext{
${ }^{16}$ In simulations not reported here but available on request, the concavity also increases with imperfect intervention.

17 As an example of risk aversion, consider a twice differentiable concave utility function, $u(D)$. Pratt (1964) showed that the intensity with which an individual dislikes the uncertainty he faces can be measured by $-u^{\prime \prime}(D) / u^{\prime}(D)$. This measure is called absolute risk aversion.
} 
Table 2

Summary of simulation results.

\begin{tabular}{|c|c|c|c|c|}
\hline $\begin{array}{c}\text { Perfect and } \\
\text { costless }\end{array}$ & $\partial E(D) / \partial \bar{f}=0$ & $\begin{array}{l}\partial \sigma_{D} / \partial m>0 \\
\partial \sigma_{D} / \partial a>0 \\
\partial \sigma_{D} / \partial \bar{f}>0 \\
\partial \sigma_{D} / \partial \sigma_{f}<0\end{array}$ & $E(D)=1000$ & $\begin{array}{l}\text { Intervention effective in reducing volatility without affecting average output } \\
\text { Effectiveness increases as the economy's inherent volatility increases }\end{array}$ \\
\hline $\begin{array}{l}\text { Perfect with } \\
\text { costs }\end{array}$ & $\begin{array}{l}\partial E(D) \partial \bar{f}>0 \\
\partial E(D) / \partial c<0\end{array}$ & $\begin{array}{l}\partial \sigma_{D} / \partial \overline{\bar{f}}>0 \\
\partial \sigma_{D} \partial c>0\end{array}$ & $E(D)<1000$ & $\begin{array}{l}\text { Intervention lowers average output and is less effective in reducing volatility } \\
\text { Higher costs decrease expected output and increase volatility } \\
\text { Randomness in costs increases volatility }\end{array}$ \\
\hline $\begin{array}{l}\text { Imperfect } \\
\text { without } \\
\text { costs }\end{array}$ & $\partial E(D) / \partial \bar{f}=0$ & $\begin{array}{l}\partial \sigma_{D} / \partial \bar{f}>0 \\
\partial \sigma_{D} / \partial \varepsilon>0\end{array}$ & $E(D)=1000$ & $\begin{array}{l}\text { Intervention effective in reducing volatility without affecting average output but less effective than } \\
\text { perfect and costless. The more imperfect the intervention, the less effective it is in reducing volatility }\end{array}$ \\
\hline $\begin{array}{l}\text { Imperfect } \\
\text { with costs }\end{array}$ & $\partial E(D) / \partial \bar{f}=0$ & $\begin{array}{l}\partial \sigma_{D} / \partial \bar{f}>0 \\
\partial \sigma_{D} / \partial \varepsilon>0\end{array}$ & $E(D)<1000$ & $\begin{array}{l}\text { Intervention reduces expected output and is less effective in reducing volatility than imperfect costless. } \\
\text { The more imperfect the intervention, the less effective it is in reducing volatility }\end{array}$ \\
\hline
\end{tabular}

This is an important theoretical result with potential practical implications. The practical implication is that there is no universal optimal regulation policy. The optimal policy varies according to the risk aversion of the regulatory authority. If we then make the plausible assumption of decreasing absolute risk aversion, we can argue against a common regulatory system for all countries. ${ }^{18}$ The argument is that because of decreasing absolute risk aversion, lower income countries have higher levels of risk aversion and thus are willing to sacrifice financial productivity for a reduction in systemic volatility while higher income countries are willing to accept more systemic risk in exchange for higher financial productivity.

\section{Conclusion}

In this article we have shown that when regulatory intervention is perfect and costless, the potential rewards in terms of reduced systemic volatility to be reaped from discretionary financial regulation are considerable. The rewards are greatest where the bands are smallest and for banking systems with the highest inherent volatility. In fact, surprisingly and counter-intuitively, over a relatively long interval, intervention actually drives systemic volatility for economies with higher intrinsic volatility below the systemic volatility for economies with lower levels of intrinsic volatility. The reason for this counter-intuitive effect is that for a given level of the rate of change in total assets higher levels of intrisic volatility increase the probability that one of the limits will be reached, thereby triggering intervention by the regulator. Thus, bankers mitigate their investment behavior more than they would if intrinsic volatility were lower. Ceteris paribus, this effect highlights the importance of regulatory competence and credibility and suggests that appropriate, stringent regulation can be advantageous for intrinsically risky banking systems.

Another interesting result is that under the plausible assumption that higher leverage increases the return on assets, we show that higher levels of return on assets $(m)$ and/or a higher investment coefficient $(a)$ increase systemic volatility at all intervention bands. Given that banks can increase their return on assets and their asset base by reducing their capital requirements, this is evidence that a system of highly leveraged banks (high investment coefficients and high return on assets) is more volatile (less stable) and less sensitive to regulatory intervention than a system with higher capital requirements.

\footnotetext{
18 Decreasing absolute risk aversion means that $\left[-u^{\prime \prime} / u^{\prime}\right]^{\prime}<0$. Taking the derivative and rearranging gives $-u^{\prime \prime} / u^{\prime}<-u^{\prime \prime \prime} / u^{\prime \prime}$. We recognize $-u^{\prime \prime \prime} / u^{\prime \prime}$ as the measure of absolute prudence. Thus, for absolute risk aversion to be decreasing, absolute prudence must be greater than absolute risk aversion. Since $-u^{\prime \prime} / u^{\prime}$ is positive, this means that $u^{\prime \prime \prime}$ must be positive as well.
}

When intervention costs are present, the price of reduced volatility is a reduction in net income. The reduction in net income is greatest just where the rewards from reduced volatility are the highest. Furthermore, when intervention costs are random, the potential for volatility reduction is substantially diminished. The potential for volatility reduction is also diminished when the timing of intervention is imperfect. In all cases, the price is highest just where the potential for volatility reduction is also the highest. Finally, and most importantly, we show that when intervention costs are present, there is no universal optimal regulatory policy. The optimal regulatory policy, measured as the intervention band, depends on the economy's level of absolute risk aversion. This result looks like an avenue with many practical implications that should be fruitfull for further research.

\section{Appendix A}

Starting from Eq. (7) in the text:

$D(t)=\frac{1}{a} \int_{t}^{\infty} e^{\frac{-(s-t)}{m a}}\left[q(t)+\int_{t}^{T} E[f(u)] d u\right] d s$

The integral in the brackets follows a Brownian motion so it can be written as a function:

$h[f(t)]=\frac{1}{a} \int_{t}^{\infty} e^{\frac{-(s-t)}{m a}} d s \int_{t}^{T} E[f(u)] d u$

The other part of the integral reduces to $m q(t)$ so that (7) becomes:

$D(t)=m q(t)+h[f(t)]$

Differentiate (A.2) and apply Ito's Lemma:

$E[d D(t)]=m d q(t)+h^{\prime}[f(t)] \alpha d t+\frac{1}{2} h^{\prime \prime}[f(t)] \sigma^{2} d t$

Take (A.3) into (1) and simplify:

$D(t)=m q(t)+m^{2} a f(t)+m a \alpha h^{\prime}[f(t)]+\frac{m a \sigma^{2}}{2} h^{\prime \prime}[f(t)]$

Take (A.4) and (A.2):

$\frac{m a \sigma^{2}}{2} h^{\prime \prime}[f(t)]+m a \alpha h^{\prime}[f(t)]-h[f(t)]=-m^{2} a f(t)$

Solving (A.5) gives:

$h[f(t)]=m^{2} a f(t)+m^{3} a^{2} \alpha+A_{1} e^{\lambda_{1} f(t)}+A_{2} e^{\lambda_{2} f(t)}$ 


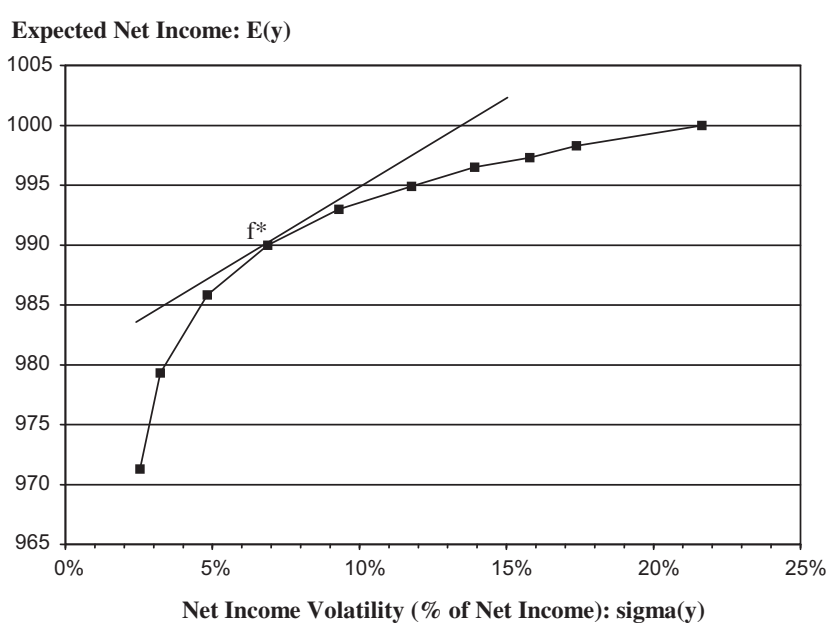

Fig. 10. Optimal band with intervention costs and risk aversion.

where $A 1$ and $A 2$ are constants and $\lambda_{1}>0$ and $\lambda_{2}<0$ are the roots to the quadratic equation in $\lambda$ :

$$
\begin{aligned}
& \frac{m a \sigma^{2}}{2} \lambda^{2}+m a \alpha \lambda-1=0 \\
& \lambda_{1}, \lambda_{2}=\frac{-m a \alpha \pm \sqrt{m^{2} a^{2} \alpha^{2}+2 m a \sigma^{2}}}{m a \sigma^{2}}
\end{aligned}
$$
text.

Finally, substituting (A.6) into (A.2) gives the expression in the

\section{Appendix B. The simulation methodology}

Simulating the foregoing model involves rewriting it in discrete time. The discrete time version of the Brownian motion for $f(t)$ is:

$\Delta f(t)=\alpha \Delta t+\sigma \tilde{y} \sqrt{\Delta t}$

where $\tilde{y}$ follows the standard normal variate and the discrete time version of (4) is:

$\Delta q(t)=f(t) \Delta t$

We use the initial values of $f$ and $q, f(0)$ and $q(0)$, and the normal variable $\tilde{y}$ to generate the other values of $f$ and $q$ and net income $D$. We start with: the interval $[0, T], f(0), q(0)$, the model's parameters, $m, a, \alpha$, and $\sigma$, the intervention parameters $\bar{f}$ and $f$ and $n$, the number of "observations" in the interval. Let $\Delta t$ be the length of the interval divided by the number of simulations: $\Delta t=\frac{T}{n}=\Delta$. The value of $f$ for each period can then be written as ${ }^{19}$

$f(i \Delta)=f((i-1) \Delta)+\alpha \Delta+\sigma \sqrt{\Delta \tilde{y}_{i}}$ for $i=1,2, \ldots, n$

Therefore

$q(i \Delta)=q((i-1) \Delta)+f((i-1) \Delta) \Delta$ for $i=1,2, \ldots, n$
The discrete time version of ( 8 ) thus becomes

$$
\begin{gathered}
D(i \Delta)=m q(i \Delta)+m^{2} a f(i \Delta)+m^{3} a^{2} \alpha+A_{1} e^{\lambda_{1} f(i \Delta)}+A_{2} e^{\lambda_{2} f(i \Delta)} \\
\text { for } i=1,2, \ldots, n
\end{gathered}
$$

where the Brownian motion oscillates between $\bar{f}$ and $f$. Thus, in our simulation, when the calculated value of $f$ is higher (lower) than $\bar{f}(f)$, we set the simulated value equal to $\bar{f}(f)$.

\section{References}

Acharya, V., 2009. A theory of systemic risk and design of prudential bank regulation. Journal of Financial Stability 5, 224-255.

Acharya, V.V., Richardson, M. (Eds.), 2009. NYU-Stern Report, "Restoring Financial Stability". John Wiley and Sons, New York.

Acharya, V., Schnabl, P., 2009. How banks played the leverage game. In: Acharya, V.V., Richardson, M. (Eds.), NYU-Stern Report, "Restoring Financial Stability". John Wiley and Sons, New York.

Adrian, T., Brunnermeier, M., 2008. CoVaR. Federal Reserve Bank of New York State Report 348.

Allen, F., Gale, D., 2000. Financial contagion. Journal of Political Economy 108, 1-33.

Allen, F., Carletti, E., Babus, A., 2009. Financial crises: theory and evidence. Annual Review of Financial Economics 1 (1), 97-116.

Borio, C., Zhu, H., 2008. Capital regulation, risk-taking and monetary policy: a missing link in the transmission mechanism? BIS Working Papers 268.

Brunnermeier, M., Crockett, A., Goodhart, C., Persaud, A., Shin, H., 2009. The Fundamental Principles of Financial Regulation. 11th Geneva Report on the World Economy.

Dasgupta, A., 2004. Financial contagion through capital connections: a model of the origin and spread of bank panics. Journal of the European Economic Association 2 (6), 1049-1084.

de Bandt, O., Hartmann, P., 2001. Systemic risk in banking: a survey. In: Goodhart, C., Illing, G. (Eds.), Financial Crisis, Contagion, and the Lender of Last Resort: A Reader. Oxford University Press, pp. 249-298.

de Vries, C., 2005. The simple economics of bank fragility. Journal of Banking and Finance 29 (4), 803-825.

Freixas, X., Parigi, B., Rochet, J., 2000. Systemic risk, interbank relations, and liquidity provision by the central bank. Journal of Money, Credit and Banking 32, 611-638.

Hellwig, M., 2008. Systemic Risk in the Financial Sector: An Analysis of the Subprime-Mortgage Financial Crisis. Max Planck Institute for Research on Collective Goods, Bonn 2008/43.

Huang, X., Zhou, H., Zhu, H., 2009. A framework for assessing the systemic risk of major financial institutions. Journal of Banking and Finance 33 (11), 2036-2049.

Lagunoff, R., Schreft, S., 2001. A model of financial fragility. Journal of Economic Theory 99 (1), 220-264.

Pratt, J., 1964. Risk aversion in the small and the large. Econometrica 32, 217-229.

Segoviano, M., Goodhart, C., 2009. Banking Stability Measures. IMF Working Paper 09/04. International Monetary Fund, Washington.

Shin, H., 2009. Financial intermediation and the post-crisis financial system. In: 8th BIS Annual Conference.

Tarashev, N., Borio, C., Tsatsaronis, K., 2009a. Allocating systemic risk to individual institutions: methodology and policy applications. BIS Working Papers.

Tarashev, N., Borio, C., Tsatsaronis, K., 2009b. The systemic importance of financial institutions. BIS Quarterly Review September.

Volker, P., Frenkel, J., 2009. Group of 30 "Financial Reform: A Framework for Financial Stability". Washington, D.C., Group of 30.

Wagner, W., 2010. Diversification at financial institutions and systemic crises. Journal of Financial Intermediation 19 (3), 373-386.

Zhou, C., 2010a. Why the micro-prudential regulation fails? The impact on systemic risk by imposing a capital requirement, <http://ssrn.com/abstract=1570644>.

Zhou, C., 2010b. Are banks too big to fail? International Journal of Central Banking 6 (34), 205-250.

\footnotetext{
19 To get a value for $f$ we have to simulate $y_{1}, y_{2}, \ldots, y_{n}$. For this we draw two uniform variates, $x_{1}$ and $x_{2}$, from 0,1 . Define $y_{1}$ and $y_{2}$ by

$y_{1}=\cos \left(2 \pi x_{2}\right) \sqrt{-2 \ln \left(x_{1}\right)}$

$y_{2}=\cos \left(2 \pi x_{1}\right) \sqrt{-2 \ln \left(x_{2}\right)}$
}

Then $y_{1}$ and $y_{2}$ are independent standard normal variables. 